BMJ Open

Diabetes

Research

\& Care

\section{Estimating the prevalence and incidence of type 2 diabetes using population level pharmacy claims data: a cross-sectional study}

To cite: Sinnott S-J, McHugh S, Whelton $\mathrm{H}$, et al. Estimating the prevalence and incidence of type 2 diabetes using population level pharmacy claims data: a cross-sectional study. BMJ Open Diabetes Research and Care 2017;5: 000288 . doi:10.1136/bmjdrc-2016000288

Received 24 June 2016 Revised 25 August 2016 Accepted 12 September 2016

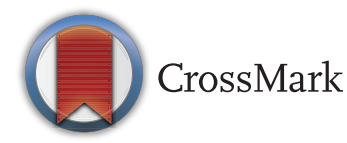

${ }^{1}$ Department of Epidemiology and Public Health, University College Cork, Cork, Ireland ${ }^{2}$ Department of Noncommunicable Disease Epidemiology, London School of Hygiene and Tropical Medicine, London, UK

${ }^{3}$ School of Dentistry, University of Leeds, Leeds, UK

${ }^{4}$ Department of Sociology, School of Social Sciences and Philosophy, Trinity College Dublin, Dublin, Ireland

${ }^{5}$ Economic and Social Research Institute, Dublin, Ireland

Correspondence to Dr Sarah-Jo Sinnott; sarah-jo.sinnott@Ishtm.ac.uk

\section{ABSTRACT}

Objective: To estimate the prevalence and incidence of type 2 diabetes using a national pharmacy claims database.

Research design and methods: We used data from the Health Service Executive-Primary Care

Reimbursement Service database in Ireland for this cross-sectional study. Prevalent cases of type 2 diabetes were individuals using an oral hypoglycemic agent, irrespective of insulin use, in 2012. Incident cases were individuals using an oral hypoglycemic agent in 2012 who had not used one in the past. Population level estimates were calculated and stratified by age and sex.

Results: In 2012, there were 114957 prevalent cases of type 2 diabetes giving a population prevalence of $2.51 \%(95 \% \mathrm{Cl} 2.49 \%$ to $2.52 \%)$. Among adults ( $\geq 15 \mathrm{yrs})$, this was $3.16 \%(95 \% \mathrm{Cl}$ $3.15 \%$ to $3.18 \%)$. The highest prevalence was in those aged $70+$ years (12.1\%). 21574 people developed type 2 diabetes in 2012 giving an overall incidence of $0.48 \%(95 \% \mathrm{Cl} 0.48 \%$ to $0.49 \%)$. In adults, this was $0.60 \%(95 \% \mathrm{Cl} 0.60 \%$ to $0.61 \%)$. Incidence rose with age to a maximum of $2.08 \%$ $(95 \% \mathrm{Cl} 2.02 \%$ to $2.15 \%)$ in people aged $65-$ 69 years. Men had a higher prevalence $(2.96 \%$ vs $2.04 \%$ ) and incidence $(0.54 \%$ vs $0.41 \%)$ of type 2 diabetes than women.

Conclusions: Pharmacy claims data allow estimates of objectively defined type 2 diabetes at the population level using up-to-date data. These estimates can be generated quickly to inform health service planning or to evaluate the impact of population level interventions.

\section{INTRODUCTION}

Diabetes mellitus is a leading cause of death globally, causing almost 4 million deaths in 2010. ${ }^{1}$ Morbidity arising from the disease is also substantial; the Global Burden of Disease study estimated a $30 \%$ increase in disability-adjusted life years for diabetes between 1990 and 2010 due to increasing

\section{Key messages}

- Many estimates for the burden of diabetes come from cohort studies and surveys, which are often not population based. There are very few estimates of incidence of diabetes globally.

- We used a national administrative pharmacy claims database to calculate prevalence and incidence of type 2 diabetes. This method captures all treated cases of diabetes and thus avoids problems with sampling and generalizing to whole populations that arise from cohort and survey methods.

- Understanding the true burden of disease in our society is essential for the planning of health services, which in turn help achieve optimal outcomes in terms of diabetes-related morbidity and mortality. Using pharmacy claims data is a straightforward method of achieving up to date estimates.

prevalence of the disease and increased longevity of those living with diabetes. ${ }^{2}$

To reduce diabetes-related mortality and morbidity, access to appropriate healthcare services for people with diabetes is a necessity. For this to be successful, up-to-date population level estimates of disease burden are required to rationally plan and deliver the required health services.

The Institute of Public Health (IPH) estimates and forecasts for the prevalence of diabetes (combined type 1 and type 2) are often cited and are a valuable resource. ${ }^{3}$ However, the most recent estimates from the IPH are based on a cross-sectional survey of adults in the Survey of Lifestyle, Attitudes and Nutrition (SLAN) which dates back to $2007 .^{34}$

Other estimates of diabetes prevalence come from The Irish Longitudinal Study of Ageing (TILDA), which is limited to those over 50 years, ${ }^{5}{ }^{6}$ the Mitchelstown cohort which was limited to adults aged 50-69 years 
in one rural area in the South of Ireland $^{7}$ and the Central Statistics Office (CSO) Quarterly National Household Survey (QNHS) from 2010. ${ }^{8}$ These estimates are based on a variety of self-reported doctor diagnosis; self-reported diabetes medication usage; or a combination of self-report and HbA1c data; and all are limited to adult populations. Furthermore, there is a scarcity of data available on the incidence of diabetes in Ireland. ${ }^{9}$

In this study, we used national pharmacy claims data to estimate the prevalence and incidence of type 2 diabetes. These data provide an objective measure of treated diabetes in the total population to complement existing sample-based estimates.

\section{METHODS}

\section{Health system}

In Ireland, access to and reimbursement for diabetes medicines occur via two publicly funded community drug schemes. The first is the General Medical Services (GMS) scheme; the main public health insurance program providing primary and secondary healthcare free at the point of access to $\sim 40 \%$ of the Irish population on a means-tested basis. ${ }^{10}$ Medicines are included under this scheme but are subject to a copayment (€2.50 currently). The second drug scheme is the longterm illness (LTI) scheme. The LTI provides free access to condition-related medicines for individuals diagnosed with any of 16 chronic illnesses including diabetes. LTI coverage is independent of income.

\section{Data}

Pharmacists dispensing medicines to all patients (adults and children) on the GMS and the LTI scheme are reimbursed by the government via the Health Service Executive-Primary Care Reimbursement Service (HSE-PCRS). We used dispensing data from the HSEPCRS database from July 2011 to December 2012. Data were available for the drug dispensed (classified by WHO Anatomical Therapeutic Chemical (WHO ATC) code), date dispensed, quantity and strength, in addition to patient age and sex.

Population denominator data for the year 2012 were population estimates derived by the CSO based on the 2011 census. $^{11}$

\section{Definitions}

Type 2 diabetes was classified as using any strength or quantity of an oral hypoglycemic agent (WHO ATC A10B), irrespective of age or insulin use. The different agents included in this study, stratified by age and sex, are given in table 1 .

\section{Calculation of incidence and prevalence}

To estimate the prevalence of type 2 diabetes, we used dispensing data for 2012. We counted the number of people in the database who met our definition of type 2 diabetes and used this as the numerator. The total population count published by the CSO was the denominator. ${ }^{11}$

To establish the annual incidence for type 2 diabetes in 2012, we used data from July 2011 to December 2012. An individual's first occurrence in 2012 meeting the definition of type 2 diabetes was referred to as the index date. A 6 month look-back period was used to rule out prior use before the index date. If no prior use of an oral hypoglycemic agent occurred in the look-back period, then the individual was an incident user of oral hypoglycemic medicines and thus an incident case. This count was used as the numerator, while the denominator was the total population count published by the CSO minus the number of prevalent of cases. ${ }^{11}$

We carried out subgroup analyses by age group ( $<15$ years, $\geq 15$ years, $15-24$ years, 25-34 years, 3544 years, $45-54$ years, $55-64$ years, $65-69$ years and $>70+$ years) and sex.

\section{RESULTS}

In 2012, 1655013 people accessed a prescription on the GMS scheme and were available in our data set. The mean

Table 1 Types of medicines used in 2012

\begin{tabular}{llllrrr}
\hline $\begin{array}{l}\text { Medicine group } \\
\text { WHO ATC code }\end{array}$ & $\begin{array}{l}\text { Biguanides } \\
\text { A10BA }\end{array}$ & $\begin{array}{l}\text { Sulfonylureas } \\
\text { n (\%) }\end{array}$ & $\begin{array}{l}\text { A10BB } \\
\text { n (\%) }\end{array}$ & $\begin{array}{l}\text { Thiazolidinediones } \\
\text { A10BG } \\
\text { n (\%) }\end{array}$ & $\begin{array}{l}\text { DPP-4 } \\
\text { A10BH } \\
\text { n (\%) }\end{array}$ & \multicolumn{1}{l}{$\begin{array}{l}\text { Other } \\
\text { A10BC, A10BF, A10BX } \\
\text { n (\%) }\end{array}$} \\
\hline Total & $907125(51.9)$ & $527,886(30.2)$ & $25658(1.5)$ & $126345(7.2)$ & $60069(3.4)$ & \multicolumn{1}{c}{$\begin{array}{r}\text { Total } \\
\text { n (\%) }\end{array}$} \\
<15 years & $1547(50.0)$ & $914(29.5)$ & $50(1.6)$ & $142(4.6)$ & $139(4.5)$ & $1747755(100.0)$ \\
15-24 years & $2959(69.7)$ & $675(15.9)$ & $57(1.3)$ & $178(4.2)$ & $212(5.0)$ & $3096(0.18)$ \\
25-34 years & $12537(67.6)$ & $3020(16.3)$ & $247(1.3)$ & $734(4.0)$ & $1088(5.9)$ & $4247(0.24)$ \\
35-44 & $48558(59.3)$ & $17542(21.4)$ & $1243(1.5)$ & $4414(5.4)$ & $4787(5.8)$ & $18554(1.06)$ \\
45-54 years & $125732(54.0)$ & $57833(24.8)$ & $3553(1.5)$ & $14760(6.3)$ & $14168(6.1)$ & $81960(4.7)$ \\
55-64 years & $236515(52.6)$ & $122554(27.3)$ & $7493(1.7)$ & $31253(6.9)$ & $20675(4.6)$ & $232955(13.3)$ \\
65-69 years & $140569(52.0)$ & $79897(29.6)$ & $4372(1.6)$ & $20725(7.7)$ & $7936(2.9)$ & $449432(25.7)$ \\
70+ years & $333853(49.3)$ & $242256(35.8)$ & $8435(1.3)$ & $53435(7.9)$ & $10600(1.6)$ & $270106(15.5)$ \\
Women & $368707(53.2)$ & $204465(29.5)$ & $9450(1.4)$ & $49794(7.2)$ & $25412(3.7)$ & $677401(38.8)$ \\
Men & $536766(51.0)$ & $322465(30.7)$ & $16073(1.5)$ & $76275(7.3)$ & $34545(3.3)$ & $692565(39.6)$ \\
\hline
\end{tabular}

Numbers are numbers of prescriptions in 2012.

Other includes sulfonamides, $\alpha$ glucosidase inhibitors and 'other' agents as defined by WHO ATC dictionary.

DPP-4, dipeptidyl peptidase-4 inhibitors. 
age was 42.9 years (SD 25.9), and the population was $54.4 \%$ women. On the LTI scheme, 68996 people accessed at least one prescription in 2012. The mean age was 48.4 years (SD 25.2), and the population was $38 \%$ women.

\section{Type 2 diabetes mellitus}

In 2012, 114957 people were classified as prevalent type 2 diabetes cases, leading to a prevalence of $2.51 \%(95 \%$ CI $2.49 \%$ to $2.52 \%$ ) in the total population. After excluding those aged $<15$ years, an adult population prevalence of $3.16 \%$ (95\% CI $3.15 \%$ to $3.18 \%$ ) was obtained (table 2). Figure 1 demonstrates how the prevalence increased with age; 55-64 years $(6.50 \%)$, $65-69$ years $(10.75 \%)$ and $70+$ years $(12.10 \%)$. Men had a higher prevalence of type 2 diabetes than women at $2.96 \%$ (95\% CI 2.94 to 2.98 ) vs $2.04 \%$ (95\% CI $2.02 \%$ to $2.06 \%)\left(\chi^{2}\right.$ test for homogeneity $\left.\mathrm{p}<0.0001\right)$.

In the same year, 21574 people developed type 2 diabetes giving an incidence of $0.48 \%(95 \%$ CI $0.48 \%$ to $0.49 \%)$. This was estimated at $0.60 \%$ (95\% CI $0.60 \%$ to $0.61 \%)$ in the population aged $\geq 15$ years. The incidence of type 2 diabetes increased with age, reaching its highest level of $2.08 \%$ (95\% CI 2.02 to 2.15) in people aged $65-69$ years. Men had a higher incidence of type 2 diabetes $(0.54 \%)$ than women $(0.41 \%)$ (table 2 and figure 1$)$.

\section{DISCUSSION}

This cross-sectional study estimated the prevalence and incidence of type 2 diabetes using population level data from a national pharmacy claims database. The overall prevalence in the adult population was $3.16 \%$. The incidence of type 2 diabetes was 6 cases per 1000 adult people in 2012.

Existing prevalence estimates pertaining to the general adult population range from $3 \%$ in the Quarterly National Household survey to $3.5 \%$ in those aged $\geq 18$ years using SLAN survey data. ${ }^{4}$ Our estimate of $3.16 \%$ is thus comparable to previous figures. In addition, our age stratified estimates for people aged $\geq 50$ years are similar to those based on TILDA using self-report of doctor diagnosis and HbA1c measures. ${ }^{56}$ However, our estimates may underestimate the true burden of diabetes given that we have excluded type 1 diabetes and we also could not account for lifestyletreated diabetes or undiagnosed diabetes. Despite this, the true prevalence rate of diabetes in Ireland is likely lower than that in the USA which was recently estimated at $8.3 \%$ in the adult population. ${ }^{12}$ In England, diagnosed diabetes in the population aged $\geq 16$ years is estimated at $5.6 \%$ from Health Survey for England data. ${ }^{13}$

The only other estimate of incidence of type 2 diabetes in Ireland is 2 cases per 1000, in contrast to the 6 cases per 1000 we found in this study. ${ }^{9}$ An American study using the National Health Interview Survey found an incidence rate of 7.1/1,000 people aged $\geq 20$ years in 2012, indicating that Irish incidence rates are below those in North America. ${ }^{12}$ A recent Danish study calculated incidence rates for every year of age. ${ }^{14}$ While it is

Table 2 Prevalence and incidence of type 2 diabetes

\begin{tabular}{|c|c|c|c|c|c|c|}
\hline & GMS & LTI & Total & Population (CSO) & Estimate (\%) & $95 \% \mathrm{Cl}$ \\
\hline \multicolumn{7}{|l|}{ Prevalence estimates } \\
\hline Total population & 81177 & 33780 & 114957 & 4585000 & 2.51 & 2.49 to 2.52 \\
\hline Total population $\geq 15$ years & 80618 & 32987 & 113605 & 3590600 & 3.16 & 3.15 to 3.18 \\
\hline$<15$ years & 721 & 1198 & 1919 & 994800 & 0.19 & 0.18 to 0.20 \\
\hline 15-24 years & 594 & 128 & 722 & 553500 & 0.13 & 0.12 to 0.14 \\
\hline 25-34 years & 1702 & 765 & 2467 & 733500 & 0.34 & 0.32 to 0.35 \\
\hline 35-44 years & 4309 & 3081 & 7390 & 700000 & 1.06 & 1.03 to 1.08 \\
\hline $45-54$ years & 8964 & 8088 & 17052 & 586300 & 2.91 & 2.87 to 2.95 \\
\hline $55-64$ years & 16466 & 13938 & 30404 & 468000 & 6.50 & 6.43 to 6.57 \\
\hline $65-69$ years & 12396 & 7120 & 19516 & 181500 & 10.75 & 10.61 to 10.90 \\
\hline $70+$ years & 41098 & 3397 & 44495 & 367800 & 12.10 & 11.99 to 12.20 \\
\hline Women & 36968 & 10231 & 47199 & 2315800 & 2.04 & 2.02 to 2.06 \\
\hline Men & 43707 & 23510 & 67217 & 2269600 & 2.96 & 2.94 to 2.98 \\
\hline \multicolumn{7}{|l|}{ Incidence estimates } \\
\hline Total population & 15788 & 5786 & 21574 & 4470043 & 0.48 & 0.48 to 0.49 \\
\hline Total population $\geq 15$ years & 15353 & 5679 & 21032 & 3476995 & 0.60 & 0.60 to 0.61 \\
\hline$<15$ years & 213 & 234 & 447 & 992881 & 0.05 & 0.04 to 0.05 \\
\hline $15-24$ years & 405 & 55 & 460 & 552678 & 0.08 & 0.08 to 0.09 \\
\hline 25-34 years & 936 & 293 & 1229 & 731033 & 0.17 & 0.16 to 0.18 \\
\hline $35-44$ years & 1584 & 819 & 2403 & 692610 & 0.35 & 0.33 to 0.36 \\
\hline $45-54$ years & 2459 & 1523 & 3982 & 569248 & 0.70 & 0.68 to 0.72 \\
\hline $55-64$ years & 3485 & 2026 & 5511 & 437596 & 1.26 & 1.23 to 1.29 \\
\hline $65-69$ years & 2406 & 971 & 3377 & 161984 & 2.08 & 2.02 to 2.15 \\
\hline $70+$ years & 5585 & 413 & 5998 & 323305 & 1.86 & 1.81 to 1.9 \\
\hline Women & 7242 & 1959 & 9201 & 2268601 & 0.41 & 0.40 to 0.41 \\
\hline Men & 8165 & 3815 & 11980 & 2202383 & 0.54 & 0.53 to 0.55 \\
\hline
\end{tabular}


Figure 1 Prevalence and

incidence of type 2 diabetes.

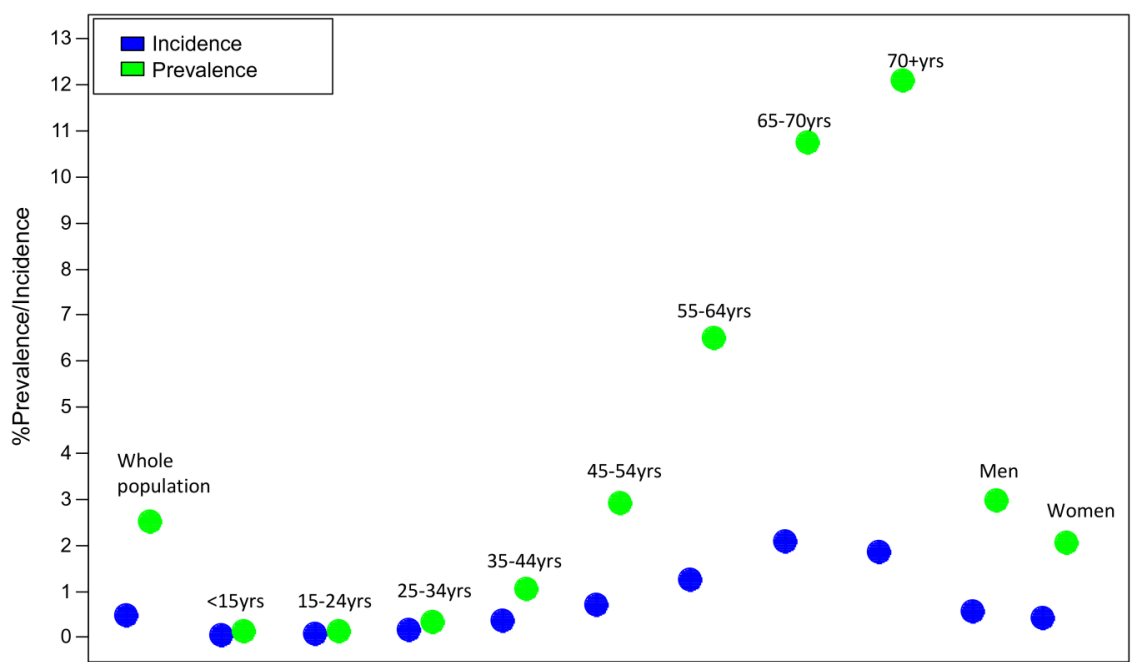

difficult to compare single age estimates with estimates for age categories, our estimates appear comparable to those in the Danish study, albeit somewhat higher in the older age groups. ${ }^{14}$ Making international comparisons is helpful to aid in understanding the plausibility of our estimates, however differences do exist between populations for demographic and methodological reasons. ${ }^{15}$

The study is limited by lack of information on undiagnosed diabetes and lifestyle-treated diabetes. Other data sources, for example the Mitchelstown Cohort and SLAN survey, provide information on undiagnosed diabetes, which can be used in tandem with our results. ${ }^{4} 7$ Unpublished data from the Mitchelstown Cohort study of over 2000 adults aged 50-69 years reveal that $\sim 7 \%$ of those with self-reported diabetes are treated with diet only. ${ }^{16}$ Although these data are not nationally representative, they provide some context on the magnitude of underestimation. Furthermore, we relied on diagnosed individuals adhering to their treatment regimens, their dispensed medications thus appearing in the pharmacy claims database. We did not anticipate non-adherence to be a major problem given that medicines are free on the LTI scheme and subject to a small copayment on the GMS scheme (€0.50 per item in 2012). ${ }^{17}$

The study is strengthened by the objective and reliable nature of the data. ${ }^{18}$ Additionally, because diabetes medicines are generally provided only through the GMS and LTI drug schemes, data on those with diagnosed and treated diabetes should be nationally complete in this database offering population level data for all ages, including children, in contrast to previous surveys and cohort studies which are limited to adults. Unfortunately, the database does not have access to diagnosis codes, thus we made the assumption that all oral hypoglycemic agents were being used to treat diabetes. A notable exception is the use of metformin for polycystic ovarian syndrome (PCOS). However, as PCOS effects only a small proportion of women of reproductive age, $\sim 8 \%$, and only some of these will be treated, any effect on our estimates is likely to be small. Further, many women with PCOS will have diabetes, and we will have intended to include them in our estimates. ${ }^{19}$ Metformin is also used in pre-diabetes, which due to lack of diagnosis codes, we have not been able to separate from our estimates. We know from our prior research that the prevalence of pre-diabetes in those aged $\geq 45$ years is $20 \%{ }^{20}$ From the most recent audit of diabetes management in General Practice, we know that $\sim 90 \%$ of those with pre-diabetes are treated with dietary intervention (unpublished). ${ }^{21}$ Thus, any bias contributed to our results from including those with metformin-treated prediabetes is likely to be inconsequential.

Our study has demonstrated the utility of routinely collected administrative claims data in calculating measures of disease burden, including incidence. The method is straightforward, and while we used data from 2012 for this study, more current data would allow estimating disease burden for the most recently completed calendar year along with establishing longitudinal trends. This approach affords advantages in real-time monitoring of disease burden and thus presents a key resource for evaluating public health interventions to reduce the prevalence and incidence of type 2 diabetes, thus informing health policy and health service planning. To address acknowledged weaknesses in using these data, estimates for prevalence and incidence should be considered in combination with crosssectional and cohort study results to account for undiagnosed and lifestyle-treated cases.

Contributors S-JS, PMK and SMcH conceived of and planned the study. S-JS carried out the analyses and wrote the paper. S-JS, PMK, SMcH, SB, RL and HW all reviewed/edited the manuscript.

Funding At the time the work was carried out, S-JS was funded under Health Research Board in Ireland under grant no. PHD/2007/16. PMK is funded under the Health Research Board Leadership Award in Diabetes (RL/2013/7). $\mathrm{SMcH}$ is funded by the Centre for Ageing and Development Research in Ireland (CARDI) Leadership Fellowship.

Competing interests None declared. 
Patient consent Obtained.

Provenance and peer review Not commissioned; externally peer reviewed.

Data sharing statement We have provided most of the raw numbers in the included table. We are happy to provide other aggregate level results for anyone who wishes to obtain them, within the limits of our own data agreements.

Open Access This is an Open Access article distributed in accordance with the terms of the Creative Commons Attribution (CC BY 4.0) license, which permits others to distribute, remix, adapt and build upon this work, for commercial use, provided the original work is properly cited. See: http:// creativecommons.org/licenses/by/4.0/

\section{REFERENCES}

1. Roglic G, Unwin N. Mortality attributable to diabetes: estimates for the year 2010. Diabetes Res Clin Pract 2010;87:15-19.

2. Murray CJ, Vos T, Lozano R, et al. Disability-adjusted life years (DALYs) for 291 diseases and injuries in 21 regions, 1990-2010: a systematic analysis for the Global Burden of Disease Study 2010. Lancet 2013;380:2197-223.

3. Balanda KP, Jordan A and McArdle E. (2006) Making diabetes count. A systematic approach to estimating population prevalence on the island of Ireland in 2005. Dublin/Belfast: Institute of Public Health in Ireland.

4. Balanda KP, Buckley CM, Barron SJ, et al. Prevalence of diabetes in the Republic of Ireland: results from The National health survey (SLAN) 2007. PLoS One 2013;8

5. Tracey M, McHugh S, Buckley C, et al. The prevalence of Type 2 diabetes and related complications in a nationally representative sample of adults aged 50 and over in the Republic of Ireland. Diabet Med 2016;33:441-5.

6. Leahy $\mathrm{S}$, O'Halloran A, O'Leary $\mathrm{N}$, et al. Prevalence and correlates of diagnosed and undiagnosed type 2 diabetes mellitus and prediabetes in older adults: findings from the Irish Longitudinal Study on Ageing (TILDA). Diabetes Res Clin Pract 2015;110:241-9.

7. Connor JM, Millar SR, Buckley CM, Kearney PM and Perry IJ, et al. 2013. The prevalence and determinants of undiagnosed and diagnosed type 2 diabetes in middle-aged irish adults. PloS one, 8(11), p.e80504.

8. Central Statistics Office. Health status and health service utilisation. Quarterly National Household Survey. Quarter 3, 2010. 2010. http:// www.cso.ie/en/media/csoie/releasespublications/documents/ labourmarket/2010/healthstatusq32010.pdf (accessed 23rd December 2016).

9. Tracey, Marsha L., et al. Epidemiology of diabetes and complications among adults in the Republic of Ireland 1998-2015: a systematic review and meta-analysis. BMC public health 16.1 (2016):1.

10. Health Service Executive. Primary care reimbursement servicestatistical analysis of claims and payments. 2012. http://www.hse.ie/ eng/staff/PCRS/PCRS_Publications/PCRSannreport12.pdf (accessed 18 Jan 2016)

11. Central Statistics Office. Population and migration estimates. 2012. http://www.cso.ie/en/media/csoie/releasespublications/ documents/population/2012/popmig_2012.pdf (accessed 23rd December 2016).

12. Geiss LS, Wang J, Cheng YJ, et al. Prevalence and incidence trends for diagnosed diabetes among adults aged 20 to 79 years, United States, 1980-2012. JAMA 2014;312:1218-26.

13. Mainous AG, Tanner RJ, Baker R, et al. Prevalence of prediabetes in England from 2003 to 2011: population-based, cross-sectional study. BMJ Open 2014;4:e005002.

14. Carstensen B, Kristensen JK, Ottosen $P$, et al. The Danish National Diabetes Register: trends in incidence, prevalence and mortality. Diabetologia 2008;51:2187-96.

15. Fazeli Farsani S, van der Aa MP, van der Vorst MM, et al. Global trends in the incidence and prevalence of type 2 diabetes in children and adolescents: a systematic review and evaluation of methodological approaches. Diabetologia 2013;56:1471-88.

16. Kearney PM, Harrington JM, Mc Carthy VJ, et al. Cohort profile: the Cork and Kerry diabetes and heart disease study. Int J Epidemiol 2013;42:1253-62.

17. Sinnott SJ, Normand C, Byrne S, et al. Copayments for prescription medicines on a public health insurance scheme in Ireland. Pharmacoepidemiol Drug Saf 2016;25:695-704.

18. Grimes T, Fitzsimons M, Galvin M, et al. Relative accuracy and availability of an Irish National Database of dispensed medication as a source of medication history information: observational study and retrospective record analysis. J Clin Pharm Ther 2013;38:219-24.

19. Sirmans SM, Pate KA. Epidemiology, diagnosis, and management of polycystic ovary syndrome. Clin Epidemiol 2014;6:1.

20. Buckley CM, Madden J, Balanda K, et al. Pre-diabetes in adults 45 years and over in Ireland: the Survey of Lifestyle, Attitudes and Nutrition in Ireland 2007. Diabet Med 2013;30:1198-203.

21. Murphy K, Mc Hugh S, Moran J. Diabetes in general practice audit report; Jun 2009-May 2010. 2011. 